\title{
Reform and Innovation of Enterprise Management under the
}

\section{Background of Big Data}

\author{
Jie Guo ${ }^{1, a}$ \\ ${ }^{1}$ Chongqing University of Science \& Technology, Chongqing City, China, 401331 \\ a email:
}

Keywords: Big Data, Management Mode, Business Intelligence, Knowledge Management, Innovation

\begin{abstract}
With the rapid development of mobile Internet and cloud computing, the intelligent terminals, application storage, video surveillance and other fields have store a large number of global data. The arrival of the big data era not only brings a huge impact on the traditional enterprise management mode, but also provides a new mode of thinking for the enterprise management mode. Based on the author's practical experience, this paper first analyzed the challenges of enterprise data processing under the environment of large data, and then put forward the innovation strategies of enterprise management mode under the environment of big data.
\end{abstract}

\section{Introduction}

At present, many advanced foreign enterprises use big data and business intelligence technology in the process of production and operation, and the data is playing a more and more important role. Under such background, the enterprise management methods are also facing challenges. Facing the rapid emergence of large scale data inside and outside the enterprise, the traditional data mining methods and tools of technology has been useless, and it can not achieve the real-time processing and analysis of a large number of data. Therefore, from the actual demand of enterprise information management, analyzing the opportunities and challenges of the big data environment, discussing the changes brought by the big data to enterprise management mode innovation have an obvious practical significance.

\section{The Challenges Faced by Enterprise Data Processing under the Environment of Big Data}

Data view of big data. In the era of big data, with the rapid development of the Internet and communication technology, the collection, storage and analysis data of the enterprise gradually increased, presenting an "explosive" growth trend. Enterprise data type is various, except the storage of structured data based on the digital text, it save semi-structured and unstructured data, such as text, web logs, audio, video, pictures, geographic information, etc., which are generated in the business activities of electronic commerce, social networking, Internet of things and so on. The existing data processing method is only applicable to structured data, but these are known as unstructured data accounted for more than $85 \%$ of the total amount of enterprise data. How a large number of unstructured and semi-structured data can be unified and integrated is one of the challenges faced by enterprise data processing.

Data integration of big data. In the enterprise information system, there are different system 
platforms. Data is stored in different business database, and the data of different business modules are difficult to realize sharing; Some companies collect, integrate and use key business data, while non critical business data may be ignored. In the big data environment, through the establishment of business intelligence to mine knowledge, we must establish a data warehouse or data mart. How to achieve cross platform data association and integration is also a huge challenge facing the enterprise.

The technical matters of big data. Big data technology issues related to data storage, processing and mining. In recent years, the information technology has gradually rose, such as cloud computing technology, interactive behavior technology and social network. Intelligent business system is a combination of network, multimedia, ontology, semantic Web, machine learning, data mining, knowledge discovery, intelligent agent and other modern high-tech. Business intelligence technologies include the collection, collation and analysis of data, etc., provide technology and methods to enable enterprises to quickly analyze data. As the core technology of the era of big data, the practical application of business intelligence in the business world involves finance, telecommunications, networking, e-commerce and other industries are not yet widely available.

Data security issues. With the increase of enterprise data and data integration, it becomes more difficult to protect the massive data. In the network space, the computing model of distributed processing makes the data more easily become the target of hacker attacks. Electronic commerce network transactions become more and more frequent, which will Increase the leakage risk of a large number of enterprises operating data, customer information, personal privacy information. In addition, if the hacker masters the enterprise data mining and other large data analysis technology, in turn, they will use these technologies to launch an attack on the enterprise. Therefore, the information security is becoming a bottleneck restricting the development of large data technology.

\section{Innovation of Enterprise Management Mode under the Environment of Big Data}

Build enterprise information platform based on business intelligence. In the era of big data, if the enterprises want to dig data information to improve the degree of intelligence, the first is to do a good job in product design, production, management, finance, logistics, sales and customer management, a series of changes in information technology. Therefore, in addition to the enterprise information within the organization to achieve office automation, it also should focus on the cultivation of information consciousness and data quality management awareness. Real and reliable data information is the foundation of enterprise management decision, and it is the key to the success of enterprise information system. In addition, enterprises should pay attention to the cultivation and introduction of business intelligence and data mining professionals. Enterprise business intelligence information platform can solve the problem of data integration across the business platform. The platform is based on data warehouse, through online analysis processing and data mining to find the knowledge of data information, and these aspects need to have data mining knowledge of talent. At the same time, enterprises should strengthen the knowledge management, because the business intelligence information platform is built on the basis of the enterprise business system.

Constructing the strategic model of enterprise data based on decision "double driving". The characteristic of the era of big data is data centered, and the business executives have been aware of the potential business value of the data. The purpose of building the data strategy of an enterprise is to be regarded as an important part of the internal assets of the enterprise, and it is the source of knowledge. As one of the three major resources of enterprises, making and implementing 
data strategies has become a top priority. Enterprises should recognize the status and role of data strategy in the enterprise business, which is of great significance to the overall operation of the enterprise, the core competitiveness of enterprises to upgrade, as well as the future development of the enterprise. The data is related to the strategic decision of the enterprise, and it can provide decision making basis for decision makers. Traditional decision is based on business driven, from the generation to the development and the last to be used, it formed a cycle. However, in the big data environment, the business intelligence platform can realize real-time monitoring and early warning, which can also drive business process, therefore, enterprises should build a "double driving" model of decision making, focus on the service driving and data driving to strengthen the strategic model of enterprise data.

Training the Chief Data Officer. CDO is short for Chief Data Officer, and it is rarely mentioned in the large domestic enterprises, even the status of CIO in the enterprise is not high, which is one of the reasons why business intelligence has failed to spread rapidly. Although CIO and CDO differ only one word, however, there is a difference between the post functions and professional quality requirements. The main role of CIO is planning enterprise IT architecture and the operation and maintenance of IT on the whole, mainly responsible for the supervision of all aspects of enterprise information resources. The main function of CDO is to take data as an important resource for enterprises, through the analysis of business data from the enterprise, the external social network review and other aspects, mine the potential value of enterprise data, providing decision reference information for enterprises. In addition, in terms of job settings, in order to deal with the opportunity and challenges of big data, enterprises need to pay attention to the cultivation and introduction of CDO personnel. Although the current big data related technologies are still immature, corporate executives should be aware of the importance of CDO, strengthen the training of enterprise employees to carry out large data related technology.

Pay attention to the knowledge management of enterprises. Knowledge management refers to the process of organization to effectively collect, develop, share and apply knowledge. For the enterprise, knowledge management is not an unfamiliar topic. Knowledge is the intangible asset of the enterprise, the process of converting data into useful information and knowledge, and it follows the experience of the network effect, .the more people share it, the more it will be worth. Many large companies believe that the value of an enterprise depends on the ability of the enterprise to create and manage knowledge. Knowledge management increases the ability of the organization to learn from its environment, and applies the knowledge to the process of the enterprise. Big data era, in essence, is the era of knowledge, but the knowledge learning environment is more complex. Knowledge management and cooperation are closely related, and the cooperation system under the environment of big data includes the cooperation environment based on the internet, such as Notes Lotus, email, instant messaging, social networking, Skype and wireless handheld devices, Wiki and virtual worlds. Data is processed and converted into information, and information is converted into knowledge through the mining of business intelligence tools. Establishing knowledge management system to collect, store, distribute and apply the knowledge, and providing access to employees for sharing and effective use can create more value for the enterprise.

\section{Conclusion}

Today, the big data related research has been extended to all aspects of economic and social development, and even referred to the height of the national strategy. Enterprise's development is related to the national economy and the people's livelihood, and the environment of the big data has brought new opportunities and challenges to the survival and development of enterprises. In view of 
the research and thinking of the relevant research team in the field of business intelligence and information management, based on the understanding of large data as well as the experience and conclusions of scientific research projects in the field of enterprise innovation management, the author suggests to take positive measures - Establishing business intelligence information platform, constructing the data strategy model of "double driving" enterprise decision making, establishing chief data officer system, strengthening enterprise knowledge management to promote the innovation of enterprise management mode.

\section{References}

[1] Cheng Gang, Li Min. Research on the cultivation mechanism of enterprise big data capacity [J]. Modern Information, 2014,03:7-11.

[2] Wang Yi, Zhao Shumei. State owned enterprise technology innovation and the research on the security strategy of the large data management of the archival science [J]. Archives Science Communication, 2014,02:63-67.

[3] Wang Zhiquan. Big data era and the transformation of enterprise financial management [J]. Finance and Accounting, 2014,06:74-75.

[4] Cheng Cheng. Research on enterprise value network innovation in Internet economy [J]. China Industrial Economy, 2013,09:82-94.

[5] Xu Yan. Enterprise human resources performance management innovation in the era of big data [J]. Jiangxi Social Science, 2016,02:182-187. 